\title{
DESEMPENHO NO SETOR PÚBLICO: ANÁLISE DAS METAS ADOTADAS PELOS MUSEUS PÚBLICOS FEDERAIS.
}

\author{
PERFORMANCE IN PUBLIC SECTOR: ANALYSIS OF THE \\ GOALS USED BY FEDERAL PUBLIC MUSEUMS
}

Telma Maia Pinheiro ${ }^{1}$

Antônio André Cunha Callado ${ }^{2}$

1

Mestre em Controladoria pela Universidade Federal Rural de Pernambuco (UFRPE), com graduação em Administração

(1996), especialização em Planejamento e Gestão Pública (2011) e extensão universitária em Introdução à Gerência de Projetos (2008) pela Faculdade de Ciências da Administração de Pernambuco - FCAP, e extensão universitária em Administração Pública da Cultura (2015) pela Universidade Federal do Rio Grande do Sul. Atualmente pertencente ao quadro de pessoal do Instituto Brasileiro de Museus - Ibram 2

Doutor em Administração na área de Estratégias Empresariais (linha de pesquisa em Finanças) pelo Programa de Pós-Graduação em Administração da Universidade Federal da Paraíba (2001) e Doutor em Administração na área de Gestão Organizacional (linha de pesquisa em Finanças) pelo Programa de Pós-Graduação em Administração da Universidade Federal de Pernambuco (2009).

\begin{abstract}
RESumo: Considerando o dever das instituições públicas de prestar contas e apresentar resultados, aliado à importância da avaliação do desempenho, o presente trabalho teve por objetivo analisar a consistência e aplicabilidade das metas adotadas pelos museus públicos federais vinculadas ao Instituto Brasileiro de Museus - IBRAM. Foram analisadas todas as metas adotadas no período de 2011 a 2015 pelos museus, classificados como unidades museológicas II e III. Ao todo foram analisadas as metas utilizadas por 16 museus, perfazendo um total de 410 metas. Para realizar a análise, as metas foram consolidadas em um único instrumento e, em seguida, analisadas cada uma individualmente, através da análise de conteúdo, quanto ao seu enunciado, sua unidade de medida e seu método de apuração. Desse modo, a partir da conjugação do resultado da análise de cada um destes três elementos, as metas foram consideradas executáveis, não executáveis e executáveis com ajustes, revelando um alto índice de falha na construção das metas adotadas pelos museus. O estudo traz contribuições teóricas para o campo museal e práticas para os profissionais da área, assim como pode contribuir para um processo de melhoria na gestão para um processo de melhoria na gestão dos museus públicos federais.
\end{abstract}

palavras-chave: Desempenho no Setor Público; Museus Públicos; Organizações culturais; Metas Institucionais.

ABSTRACT: Considering the obligation of public institutions to be accountable and present results, together with the importance of performance evaluation, this study aimed to analyze the consistency and applicability of the goals adopted by federal public museums linked to the Brazilian Institute of Museums (IBRAM). All the goals adopted in the period from 2011 to 2015 by museums, classified as museological units II and III were analyzed. In all, the goals used by 16 museums were analyzed, making a total of 410 goals. In order to perform the analysis, the goals were consolidated in a single instrument and then analyzed individually, through content analysis, as to their statement, unit of measure and method of calculation. Thus, from the combination of the results of the analysis of each of these three elements, the goals were considered as executable, not executable and executable with adjustments, revealing a high failure rate in the construction of the goals adopted by the museums. The study brings theoretical contributions to the field of museums and practices for professionals in the area, as well as contributing to a process of improvement in management for a process of improvement in the management of federal public museums.

KEYwORDs: Performance in the public sector; Museums; Cultural organizations. Institutional Goals. 


\section{INTRODUÇÃO}

A Nova Gestão Pública introduziu na administração pública técnicas de gestão e planejamento já consagradas no setor privado com o intuito de melhorar a qualidade na prestação do serviço, otimizar a utilização dos recursos públicos, instituir uma gestão estratégica voltada para resultados e avaliar o desempenho das instituições públicas.

De acordo com Silva e Drumond (2004), o estímulo à avaliação desempenho na gestão pública requer cada vez mais a mensuração dos objetivos, metas e resultados alcançados, isto em todo o âmbito da administração pública: federal, estadual e municipal. Vale ressaltar que esta mensuração reflete na transparência da forma como os recursos públicos são gastos.

Entretanto, a mensuração do desempenho no setor público ainda se mostra pouco explorada teórica e empiricamente quando aplicada em setores mais específicos (NOGUEIRA; GÓIS; PACHECO, 2010), como na área da Cultura, onde a utilização de técnicas mais aprimoradas de gestão ainda não é amplamente adotada por instituições, tendo como exemplo os museus públicos federais.

Além do fato de nem todos os setores utilizarem técnicas de gestão mais aprimoradas e eficientes, em alguns casos, a avaliação de desempenho é adotada pelas instituições públicas como um mero procedimento formal, realizada apenas para cumprir uma determinação legal (ALONSO, 1999), em outros, a diversidade de avaliações de desempenho acaba contribuindo para perda de foco e propósito da própria avaliação (SUZUKI; GABBI, 2009).

Desta forma, com o intuito de poder trazer contribuições teóricas para o campo museal e de organizações culturais, assim como práticas para os profissionais da área, e considerando a pouca atenção dada pela literatura à gestão em museus, por ser um campo ainda restrito quanto a aplicação de instrumentos de gestão mais inovadores, o presente estudo teve como objeto de pesquisa analisar a consistência e aplicabilidade das metas adotadas pelos museus públicos federais, classificados como unidades museológicas I, II e III, vinculados ao Instituto Brasileiro de Museus - IBRAM.

O Instituto Brasileiro de Museus - IBRAM é uma autarquia pública federal vinculada ao Ministério da Cultura (MinC), criada em janeiro de 2009, pela Lei n⿳o 11.906, que sucedeu o Instituto do Patrimônio Histórico e Artístico Nacional (IPHAN) nos direitos, deveres e obrigações relacionados aos museus federais e tem como missão valorizar os museus e promover o campo museológico a fim de garantir o direito à memória, à universalidade do acesso aos bens culturais e o respeito à diversidade, sendo responsável pela administração direta de $28 \mathrm{mu}$ seus federais, subdivididos em unidades museológicas I, II e III.

Neste trabalho foram analisadas as metas de 16 museus no período de 2011 a 2015, perfazendo um total de 410 metas. As metas foram consolidadas em um instrumento único e analisadas individualmente 
quanto ao seu enunciado, unidade de medida e método de apuração, e na sequência, com base nesta análise foi realizado o seu diagnóstico.

Segundo Putnam (2007), uma avaliação criteriosa do desempenho institucional tem que preencher quatro requisitos rigorosos: tem que ser abrangente; tem que ser internamente coerente; tem que ser confiável; e tem que corresponder aos objetivos e aos critérios dos protagonistas e dos membros da instituição, o que nem sempre acontece. O exame da mudança estrutural das organizações públicas brasileiras abre espaço para discussão de ferramentas que auxiliem a accountability e a gestão pública empreendedora, como por exemplo, o uso de critérios de desempenho para auferir e agregar resultados à Administração.

Para Galdino, Guamarães e Carmo Filho (2015), não existe gestão pública moderna empreendedora sem gestão orçamentária eficiente e eficaz, baseada na análise de desempenho auferido por meio de índices físicos e qualitativos.

Para ser eficaz, o governo muitas vezes tem que ser previdente e antecipar-se a demandas que ainda não foram articuladas. Os resultados da ação governamental podem não ser aqueles que os proponentes esperavam. No entanto, o desempenho institucional é importante porque, afinal, a qualidade do governo interessa à vida das pessoas (PUTNAM, 2007; SILVA, 2009).

Alcançar uma boa prática de gestão pública por resultados não implica somente a implementação de mecanismos de avaliação institucional. A gestão pública por resultados é viabilizada por diversos mecanismos gerenciais, começando pelo planejamento estratégico das ações governamentais - sejam elas organizadas em projetos ou programas; ampliação da flexibilidade gerencial; desenvolvimento de indicadores de desempenho; e, por fim, a avaliação de desempenho, que além da medição das metas estabelecidas, fornece subsídios para retroalimentação de informações para o desenvolvimento de futuras metas gerenciais (CORRÊA, 2007).

Os sistemas de medição de desempenho (SMDs) devem estar alinhados com os objetivos estratégicos para que possam ajudar as instituições a alcançar seus objetivos e metas, bem como melhorar a maneira como os recursos são gastos (MAIA; OLIVEIRA; MARTINS, 2008).

Com base em Rafaeli e Muller (2007), uma das dificuldades das organizações, principalmente no que diz respeito ao setor público, é unir sistemáticas que sozinhas não atingem o resultado esperado, pois a confirmação do bom desempenho da organização está vinculada ao elo entre os objetivos propostos e o que é efetivamente realizado. Outra dificuldade está associada à escolha dos indicadores de desempenho que permitem medir o desempenho em relação ao objetivo principal da entidade. Na visão de Rogers e Badham (1994), o uso de indicadores de desempenho deve ser visto como uma das principais atividades administrativas, tendo em vista que é um instrumento essencial à me- 
lhoria da qualidade do serviço, do produto e da vida na organização (JULIÃO; LIBONATI; SANTOS, 2012).

Além disso, até o presente momento, a literatura não possui pesquisas anteriores que tenham analisado a adoção de metas de desempenho no âmbito de museus públicos brasileiros, o que configura justificativa da realização desta pesquisa, bem como sua principal contribuição para a literatura.

Neste contexto, considerando a importância do planejamento estratégico, do estabelecimento de metas e da avaliação do desempenho no setor público, e especialmente a existência de poucos trabalhos acadêmicos relacionados à gestão em museus públicos, surgiu um questionamento sobre as metas adotadas por estas instituições, e que representou o problema de pesquisa do presente trabalho: as metas que vêm sendo adotadas pelos museus públicos federais são consistentes e aplicáveis para a avaliação do desempenho?

Diante do exposto, espera-se que os resultados obtidos com este trabalho possam contribuir para um processo de melhoria na gestão dos museus, especialmente na gestão, desempenho e resultados dos museus públicos federais.

\section{REVISÃO DA LITERATURA}

\section{A NOVA GESTÃO PÚBLICA E A GESTÃO POR RESULTADOS}

A Nova Gestão Pública (NGP) preconiza o modelo de Gestão por Resultados, defendendo a flexibilização dos instrumentos de gestão e a orientação das instituições e de seus agentes públicos para o alcance de resultados (GOMES, 2009).

A reforma gerencial do Estado é a segunda reforma administrativa vivida pelo moderno Estado capitalista. Na segunda metade do século XIX, os países capitalistas mais avançados empreenderam a primeira grande reforma administrativa - a reforma do serviço público ou reforma burocrática - transformando o Estado em gerencial. A experiência brasileira de reforma gerencial foi iniciada em 1995 (BRESSERPEREIRA, 2008).

A emenda constitucional da reforma administrativa brasileira (EC 19) foi remetida ao Congresso Nacional em agosto de 1995. À emenda seguiu-se a publicação de um documento sobre a reforma administrativa - O Plano Diretor da Reforma do Estado -, cuja proposta é transformar a administração pública brasileira, de burocrática, em gerencial (BRESSER-PEREIRA, 2006).

A qualidade do serviço público era sinônimo do cumprimento estrito de regras procedimentais. Priorizava-se uma organização centralizada, com ênfase em procedimentos e insumos. Entretanto, transformações sociais e a conjuntura econômica levaram o setor público a passar por reformas que priorizaram não mais uma lógica procedi- 
mental, mas uma lógica de resultados (OECD, 2004; SUZUKI; GABBI, 2009).

Souza et al. (2008) enfatizam que a Emenda Constitucional $\mathrm{n}^{\mathrm{o}}$ 19/1998, que trata sobre princípios e normas de gestão pública para controle financeiro de modo a direcionar os gestores públicos à busca da eficiência e eficácia, tomando por base as premissas presentes na Lei Complementar $\mathrm{n}^{\mathbf{0}}$ 101/2000 (Lei de Responsabilidade Fiscal), impôs aos gestores a necessidade de avaliação do desempenho das instituições públicas.

A busca pela Excelência em Gestão Pública reforça a necessidade da adoção de um planejamento estratégico, de uma visão estratégica sobre a gestão. Essa visão estratégica significa o estabelecimento de procedimentos estratégicos, com formulação de objetivos preestabelecidos e orientadores das ações nos diversos níveis da organização, com possibilidade de mensuração e avaliação dos resultados previamente esperados (PERDICARIS, 2009).Desta forma, surge a Gestão orientada para Resultados que é considerada uma poderosa ferramenta metodológica de monitoramento e avaliação das ações dos governos em sistemas políticos democráticos.Avaliar os resultados obtidos nas ações de governo, respeitando as dimensões de eficiência, eficácia e efetividade, permite aos agentes políticos estabelecer correções nos rumos dos seus processos de trabalho, como também propicia oportunidades de desenvolver estratégias de acompanhamento aos cidadãos (BRASIL, 2014).

Dentro da perspectiva da dimensão de resultados que se espera, a aplicação dos recursos públicos gera os resultados esperados tanto para a sociedade, quanto para o mercado e o próprio setor público. Assim, a gestão orientada para Resultados é considerada uma ferramenta metodológica de monitoramento e avaliação das ações dos governos em sistemas políticos democráticos.

Neste sentido, avaliar os resultados obtidos nas ações de governo, respeitando as dimensões de eficiência, eficácia e efetividade, permite aos agentes políticos estabelecer correções nos rumos dos seus processos de trabalho, como também propicia oportunidades de desenvolver estratégias de acompanhamento aos cidadãos (MP/SEGEP, 2014).

O conceito de Gestão para Resultados não se restringe apenas em formular resultados que satisfaçam às expectativas dos legítimos beneficiários da ação governamental de forma realista, desafiadora e sustentável. Requer, também, alinhar os arranjos de implementação para alcançar a construção de mecanismos de monitoramento e avaliação que possam promover o aprendizado, a transparência e a responsabilização (SEGE, 2009).

Alcançar uma boa prática de gestão pública por resultados não implica somente a implementação de mecanismos de avaliação institucional. A gestão pública por resultados é viabilizada por diversos mecanismos gerenciais, começando pelo planejamento estratégico das ações governamentais - sejam elas organizadas em projetos ou programas; ampliação da flexibilidade gerencial; desenvolvimento de 
indicadores de desempenho; e, por fim, a avaliação de desempenho, que além da medição das metas estabelecidas, fornece subsídios para retroalimentação de informações para o desenvolvimento de futuras metas gerenciais (CORRÊA, 2007).

A avaliação de desempenho, inicialmente prevista no Decreto $\mathrm{n}^{\mathrm{o}}$ 2.829 e na lei do PPA 2000-2003, é uma das etapas mais importantes do ciclo de gestão no Governo Federal. Seu objetivo é assegurar o aperfeiçoamento contínuo dos programas e do plano, provendo subsídios para corrigir falhas de concepção e execução, atualizar objetivos e metas em relação às demandas da sociedade e garantir que os resultados desejados para o público-alvo ocorram efetivamente.

A avaliação está orientada para a obtenção de resultados e se realiza uma vez por ano, tendo como referência o exercício anterior. No ciclo de gestão, a avaliação é seguida da revisão anual dos programas, da elaboração da Lei de Diretrizes Orçamentárias e da elaboração e execução da Lei Orçamentária Anual. Os resultados da avaliação contribuem para a realização de cada uma dessas etapas, tornando mais consistente a alocação de recursos públicos federais aos bens e serviços demandados pela sociedade.

Os modelos de gestão por resultados aplicados no Brasil ainda são recentes, justificando a necessidade de avaliação quanto à efetividade dos indicadores utilizados na avaliação de desempenho nesse processo (GONZAGA, 2014).

Então, para que o processo de gestão orientada por resultados ocorra, os governantes devem criar mecanismos de aferição do desempenho, da satisfação dos usuários e de controle social, com incentivos profissionais vinculados à produtividade e eficiência que, articulados, configuram as condições indispensáveis para a responsabilização dos gestores públicos (ARAÚJO, 2010).

\section{DESEMPENHO NO SETOR PÚBLICO}

A preocupação com a avaliação de desempenho é instituída na Constituição Federal de 1988 com a Reforma Administrativa de 1995, mediante a introdução da figura do contrato de gestão (art. 37, inciso XXII, parágrafo $8^{\circ}$ ). Esta reforma é orientada pela visão de um Estado menos intervencionista e mais gerencial. A preocupação com a melhoria do desempenho se refletiu também na inclusão do princípio de eficiência na administração pública, na criação de novas figuras institucionais (agências executivas, agências reguladoras, e organizações sociais). (SUZUKI; GABBI, 2009).

Para Suzuki e Gabbi (2009) e Heinrich (2003), a avaliação de desempenho deve servir ao propósito de ajudar os gestores a entender como suas ações e decisões estão ligadas aos resultados obtidos e quais fatores contextuais ou externos podem limitar ou aumentar a efetividade de sua gestão. Nesse contexto, a avaliação de desempenho serve para melhorar a gestão das ações do governo, dos serviços públicos e 
das políticas públicas (JULIÃO, 2014).

A necessidade de avaliar o desempenho das organizações públicas ganhou força com a Emenda Constitucional no $19 / 98$, que dispôs sobre princípios e normas da gestão pública, conduzindo os gestores públicos a busca da eficácia e eficiência gerencial, bem como através da Lei Complementar n⿳o 101/oo (a Lei de Responsabilidade Fiscal), que estabeleceu parâmetros para uma gestão pública responsável, transparente, sujeita a limites de gastos e de endividamento e ao cumprimento de metas (JULIÃO, 2014).

Em 2008, a Lei no 11.784 reestruturou o Plano Geral de Cargos do Poder Executivo e instituiu a sistemática para avaliação de desempenho dos servidores da administração pública federal direta, autárquica e fundacional, entre outras disposições. A regulamentação desta lei

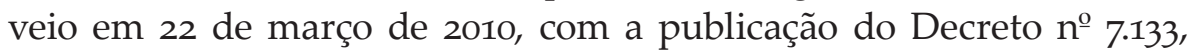
de 19 de março de 2010 , o qual estabeleceu critérios e procedimentos gerais a serem observados para a realização das avaliações de desempenho individual e institucional e para o pagamento de 49, de um total de 87 gratificações de desempenho hoje vigentes e pagas no âmbito da administração pública federal direta, autárquica e fundacional.

Os principais aspectos inovadores dessas legislações dizem respeito à vinculação entre desempenho institucional e individual por meio do desdobramento das metas no plano de trabalho, ao acordo de compromissos individuais e de equipe e à obrigatoriedade de instituição de comissão de acompanhamento.

As metas de resultado fixadas no planejamento devem ser alcançadas pelo gestor público e representam o critério básico para a avaliação do desempenho de todas as áreas de responsabilidade da entidade. Assim, é possível avaliar os resultados dos serviços, e atividades de cada uma das unidades, da entidade como um todo e, também, dos respectivos responsáveis pela gestão (SOUZA et al., 2008).

A norma citada distingue dois aspectos de desempenho a serem avaliados: o institucional e o individual. Este consiste na aferição dos fatores que refletem as competências (conhecimentos, habilidades e atitudes) verificadas no desempenho individual das tarefas, atividades ou projetos. Enquanto que o primeiro é composto por critérios e fatores que refletem a contribuição das equipes para o cumprimento das metas intermediárias e os resultados alcançados pela instituição como um todo (metas globais) (SEGEP, 2013; IBAMA, 2011).

Partindo dos dois grandes objetivos gerais, podem-se detalhar alguns dos objetivos específicos mais comuns da avaliação de desempenho, como por exemplo:

- Alinhar os processos de trabalho com a missão e com os objetivos estratégicos da instituição, buscando vincular a atuação do servidor e das equipes com o alcance das metas institucionais;

- Subsidiar o desenvolvimento de programas de capacita- 
ção, por meio da identificação de necessidades de aprendizagem e do incentivo ao aperfeiçoamento profissional, visando a ampliar a qualificação dos servidores;

- Dar apoio ao processo de revisão do planejamento estratégico;

- Identificar necessidades de adequação funcional relacionadas a problemas de adaptação ao cargo, à função ou à instituição;

- Democratizar o ambiente de trabalho, estabelecendo um diálogo contínuo com servidores e equipes a respeito dos resultados desejados pela instituição, pelos cidadãos e pela sociedade, acompanhando a superação dos desafios propostos e articulando consensualmente as correções de rumo necessárias;

- Analisar os processos de trabalho e diagnosticar melhorias visando a proporcionar insumos para o desenvolvimento organizacional e para o aperfeiçoamento da prestação dos serviços públicos (SEGEP, 2013, p. 17).

Desta forma, a avaliação de desempenho institucional tem por objetivo aferir o alcance das metas institucionais, segmentadas em metas globais e metas intermediárias, estabelecidas no planejamento estratégico ou no plano de metas institucionais e, para tanto, poderá levar em consideração projetos e atividades prioritárias e estratégicas, condições especiais de trabalho, além de outras características específicas, conforme o art. $5^{\underline{0}}$ do Decreto $n^{\underline{0}}$ 7.133/2010 e o art. 12 da Orientação Normativa $\mathrm{n}^{\mathrm{o}}$ 07/2011.

No setor público, onde a prática mais comum tem sido a avaliação ligada ao controle tendo como premissa básica o cumprimento dos requisitos legais, o processo de avaliação é mais complexo, pois deve ainda considerar os resultados sociais gerados. Assim, a natureza da avaliação da gestão do setor público tem um foco diferenciado do setor privado que é predominantemente administrativo (OLIVEIRA, 2009).

Vale ressaltar a diferença entre avaliação de resultados e desempenho, onde a primeira é a simples verificação do resultado obtido por determinado serviço. Já a segunda requer a comparação entre um resultado realizado e o planejado. Avaliar um desempenho é verificar se o resultado obtido alcançou a expectativa de resultado fixada quando do planejamento. Com base nesse resultado, pode-se julgar a eficácia da gestão (SOUZA et al., 2008).

Em síntese, a avaliação do desempenho institucional será composta por critérios e fatores que reflitam a contribuição das equipes de trabalho para o cumprimento das metas intermediárias e dos resultados alcançados pela organização como um todo (art. 143 da Lei $n^{\circ}$ $11.784 / 08)$. 
Embora a adoção de modelos de gestão de desempenho nas organizações públicas seja comum, muitos desafios ainda existem. Esses modelos estão sendo utilizados extensivamente para fornecer informações a gabinetes de planejamento e de orçamento, mas com poucos resultados práticos tanto em decisões estratégicas quanto para incentivo de projetos, o que é afetado por questões políticas (AMMONS; RIVENBARK, 2008 apud FREITAS et al., 2009).

\section{PROCEDIMENTOS METODOLÓGICOS}

TIPIFICAÇÃO

Este capítulo apresenta a metodologia da pesquisa que foi adotada para este estudo, caracterizando a sua tipologia, o detalhamento das etapas do desenvolvimento, a descrição do contexto, os procedimentos e os instrumentos que foram utilizados para a coleta e análise de dados.

De acordo com o propósito de analisar as metas que vêm sendo adotadas pelos museus, esta pesquisa é caracterizada como exploratória, visto que há uma carência de estudos sobre desempenho em museus, e que esta pesquisa buscou investigar o fenômeno e descrevê-lo tal como ocorre.

Gil (1999) destaca a importância de pesquisas exploratórias uma vez que elas têm a finalidade de desenvolver, esclarecer e modificar conceitos e idéias, bem como formular problemas mais precisos ou hipóteses pesquisáveis em estudos posteriores. Andrade (1999) complementa este entendimento sobre pesquisas exploratórias ao afirmar que elas visam agregar informações sobre um determinado assunto com a finalidade de definir objetivos, formular hipóteses ou descobrir novos enfoques a serem investigados.

Ainda sobre pesquisas exploratórias, Vergara (2003) considera que, dada sua natureza, elas não comportam hipóteses iniciais, mas que podem surgir ao longo da realização da pesquisa.

De acordo com a problemática da pesquisa, esta pesquisa tem abordagem predominantemente qualitativa, visto que concentrar-se-á na compreensão detalhada das metas utilizadas pelos museus. Entretanto, existe a necessidade de se fazer alusão ao uso, concomitante, da pesquisa quantitativa, posto que foi empregada a estatística descritiva para a análise de alguns dados inerentes à recorrência das metas utilizadas e a sua relação com as áreas de trabalho dos museus.

Desse modo, é interessante recorrer ao que argumenta Creswell (2010) quando faz referência à pesquisa de métodos mistos, utilizando a combinação de abordagens quantitativas e qualitativas. A adoção de um método misto prioriza as características mais evidentes das pesquisas quantitativas e qualitativas, auxiliando em uma melhor percepção acerca da pesquisa ao conjugar estas duas abordagens.

Vale reforçar que uma pesquisa que tenha uma abordagem predominantemente qualitativa poderá relacionar-se bem com a utili- 
zação da abordagem quantitativa no que diz respeito a determinados aspectos da pesquisa (NEVES; DOMINGUES, 2007, p. 19). Ainda, com relação ao emprego das duas abordagens, Fonseca (2002) afirma que a utilização conjunta das duas abordagens, qualitativa e quantitativa, proporciona a obtenção de mais informações do que se poderia conseguir isoladamente.

De acordo com o propósito de analisar as metas que vêm sendo adotadas pelos museus, esta pesquisa é caracterizada como exploratória e descritiva, visto que há uma carência de estudos sobre desempenho em museus, e que esta pesquisa buscou investigar o fenômeno e descrevê-lo tal como ocorre.

\section{UNIVERSO DA PESOUISA}

O IBRAM autarquia é responsável pela Política Nacional de Museus (PNM) e pela melhoria dos serviços do setor, como o aumento de visitação e arrecadação dos museus e o fomento de políticas de aquisição, sendo responsável pela administração direta de 30 museus federais, subdivididos em unidades museológicas I, II e III. Esta classificação foi determinada à época da criação do IBRAM, de acordo com a quantidade de cargos de confiança e funções gratificadas destinadas às unidades museológicas, sem considerar a estrutura física e o acervo dos museus, permanecendo atualmente esta mesma classificação.

Os museus classificados como museus unidade I são unidades gestoras orçamentárias e possuem autonomia financeira, podem realizar suas ações e executar seus projetos, sem a dependência administrativa do IBRAM. Já as unidades II e III, escolhidas como objeto deste estudo, não são unidades gestoras e mantêm uma forte relação de dependência com o IBRAM para realização de suas ações, execução de projetos e contratação de serviços, fato que afeta diretamente a gestão destas unidades.

Para a operacionzalização desta pesquisa foram considerados todos os museus classificados como unidades museais II e III, que compõem atualmente a estrutura do Instituto Brasileiro de Museus (IBRAM), perfazendo um total de 16 unidades de análise, das quais nove (9) correspondem às unidades museais II e sete (7), as unidades museais III (Quadro 1). 
QUADRO 1 - Unidades museais II e III vinculadas ao IBRAM

\begin{tabular}{|c|c|}
\hline Museus Unidades II & Museus Unidades III \\
\hline $\begin{array}{l}\text {-Museu Casa de Benjamin } \\
\text { Constant } \\
\text { - Museu da Abolição } \\
\text { - Museu do Diamante } \\
\text { - Museu do Ouro - Casa Borba } \\
\text { Gato } \\
\text { - Museu Regional de São João } \\
\text { del-Rei } \\
\text { - Museu Victor Meirelles } \\
\text { - Museus Paraty } \\
\text { - Museu de Arte Sacra de Paraty } \\
\text { - Forte Defensor Perpétuo de Paraty } \\
\text { - Museu das Missões } \\
\text { - Museus Goiás } \\
\text { - Museu das Bandeiras } \\
\text { - Museu Casa da Princesa } \\
\text { - Museu de Arte Sacra da Boa Morte }\end{array}$ & $\begin{array}{ll}\text { - } & \text { Museu de Arte Religiosa e } \\
\text { - } & \text { Tradicional de Cabo Frio } \\
& \text { Alcântara } \\
\text { - } & \text { Museu Socioambiental de } \\
& \text { Itaipu } \\
\text { - } & \text { Museu Regional Casa dos } \\
& \text { Ottoni } \\
\text { - } & \text { Museu Regional de Caeté } \\
\text { - } & \text { Museu Solar Monjardim } \\
\text { Museu Casa da Hera }\end{array}$ \\
\hline
\end{tabular}

A escolha deste universo ocorreu de forma intencional, considerando as características comuns entre estas unidades escolhidas, especialmente por manterem um alto grau de dependência administrativa com o IBRAM para realização de suas ações, execução de projetos e contratação de serviços, por não possuírem autonomia financeira e por apresentarem uma estrutura organizacional semelhante e reduzida com relação aos níveis hierárquicos e corpo funcional.

\section{COLETA DE DADOS E INFORMAÇÕES}

Para este estudo, foram utilizados dados e informações obtidas junto ao IBRAM, sendo utilizadas fontes de dados secundárias, composta por documentos institucionais relacionados às unidades museológicas em estudo: os Planos de Trabalho, referentes ao período de 2011 a 2015. Estes documentos representam as evidências do estudo que subsidiaram as análises qualitativas e quantitativas.

Com relação aos documentos a serem analisados, o Plano de Trabalho é um instrumento de avaliação de metas e desempenho no setor público, nasce do desdobramento das metas globais e intermediárias e destas em metas individuais. No plano de trabalho encontram-se registradas, formalmente, as metas das unidades museais e, em decorrência desta, as metas de desempenho individual.

Vale ressaltar, que os museus apenas são demandados a fornecerem as metas de suas unidades quando o IBRAM inclui as metas das unidades museais em suas metas intermediárias. Assim, como as metas dos museus não foram incluídas nas metas intermediárias do IBRAM no ano de 2013, não houve demanda aos museus para o envio de suas metas institucionais. Com exceção dos museus Casa Histórica de Alcântara, Arte Religiosa e Tradicional e Museu Victor Meirelles, que enviaram suas metas em 2013, os demais os museus não enviaram suas metas institucionais referentes a 2013. 
Os museus são responsáveis por estabelecerem as metas da sua unidade (metas institucionais), assim como as metas de desempenho individual da sua equipe de trabalho. Desta forma, com o Plano de Trabalho, foi possível identificar as metas que foram adotadas pelas unidades museais II e III no período em estudo.

\section{TÉCNICA DE ANÁLISE}

Para a análise dos dados e informações coletadas por meio do levantamento documental serão utilizadas as técnicas de análise de conteúdo e a estatística descritiva.

Assim, a etapa inicial da pesquisa consistiu na análise sistemática dos dados documentais, visando realizar um levantamento das metas utilizadas. A posteriori, foi realizado o tratamento das informações por meio da análise de conteúdo, visto que os dados obtidos com os produtos documentais foram organizados com a finalidade de auxiliar na investigação sobre a consistência das metas quanto ao seu objetivo e métrica.

Dessa forma, a próxima etapa foi a categorização das metas utilizadas pelos museus, a partir da análise dos dados, que permitiu verificar a consistência e aplicabilidade das metas. O Quadro 2 apresenta as classificações utilizadas para realizar a análise dos quatro elementos que compõem as metas dos museus: enunciado, unidade de medida, método de apuração e fonte de informação. A atribuição das classificações para os três elementos analisados (enunciado, unidade de medida e método de apuração) foi operacionalizada considerando os aspectos descritos inerentes a cada um deles.

QUADRO 2 - Aspectos de análise e classificação

\begin{tabular}{|c|c|c|}
\hline $\begin{array}{l}\text { Elemento } \\
\text { analisado }\end{array}$ & Classificação & Aspectos considerados \\
\hline \multirow{3}{*}{ Enunciado } & Compreensível & $\begin{array}{l}\text { Texto claro, objetivo e coerente e que indique } \\
\text { uma ação ou objetivo a ser alcançado. }\end{array}$ \\
\hline & Demanda ajuste & $\begin{array}{c}\text { Evidencia a ação ou objetivo a ser alcançado, } \\
\text { porém falta clareza, objetividade ou coerência } \\
\text { no texto, ou alinhamento com a unidade de } \\
\text { medida e/ou método de apuração. }\end{array}$ \\
\hline & Incompreensível & $\begin{array}{l}\text { Texto sem objetividade ou foco, não sendo } \\
\text { possível compreender qual a meta pretendida. }\end{array}$ \\
\hline \multirow{3}{*}{$\begin{array}{l}\text { Unidade de } \\
\text { medida }\end{array}$} & Operacionável & $\begin{array}{l}\text { Elemento determinado, tangível, passível de } \\
\text { mensuração e relacionado com o enunciado da } \\
\text { meta. }\end{array}$ \\
\hline & Demanda ajuste & $\begin{array}{l}\text { Elemento determinado, passível de } \\
\text { mensuração, mas não está claramente } \\
\text { relacionado com o enunciado da meta. }\end{array}$ \\
\hline & Não operacionável & $\begin{array}{c}\text { Elemento impreciso e/ou não é passível de } \\
\text { mensuração. }\end{array}$ \\
\hline \multirow{3}{*}{$\begin{array}{l}\text { Método de } \\
\text { apuração }\end{array}$} & Calculável & $\begin{array}{l}\text { Relação matemática válida, compatível com a } \\
\text { unidade de medida e o enunciado da meta. }\end{array}$ \\
\hline & Demanda ajuste & $\begin{array}{l}\text { Relação matemática mal formulada ou não } \\
\text { compatível com a unidade de medida. }\end{array}$ \\
\hline & Não calculável & $\begin{array}{c}\text { Não há informação, ou não há relação } \\
\text { matemática válida e nem relação com a } \\
\text { unidade de medida e/ou com o enunciado da } \\
\text { meta. }\end{array}$ \\
\hline
\end{tabular}


FONTE: Os autores (2018).

Para alcançar o diagnóstico da meta, foi realizada a análise e classificação individual dos seus elementos essenciais: enunciado, unidade de medida e método de apuração. Cabe ressaltar que o enunciado foi o elemento norteador para a análise da unidade de medida e método de apuração, e que a fonte de informação foi analisada separadamente por não ser um elemento essencial que compõe a meta, sendo apenas uma fonte de comprovação ou não de sua efetivação. Assim, o diagnóstico da meta baseou-se na composição da classificação dos seus três elementos essenciais, apresentados no Quadro 2,conforme disposto no quadro 3 .

QUADRO $_{3}$ - Guia de Diagnóstico das Metas

\begin{tabular}{|c|c|c|c|}
\hline $\begin{array}{c}\text { Diagnóstico da } \\
\text { Meta }\end{array}$ & Enunciado & $\begin{array}{l}\text { Unidade de } \\
\text { Medida }\end{array}$ & $\begin{array}{l}\text { Método de } \\
\text { Apuração }\end{array}$ \\
\hline 1. Executável & Compreensível & Operacionável & Calculável \\
\hline \multirow{9}{*}{$\begin{array}{l}\text { 2. Executável com } \\
\text { Ajuste }\end{array}$} & \multirow{5}{*}{ Compreensível } & Operacionável & Demanda ajuste \\
\hline & & Operacionável & Não calculável \\
\hline & & Não operacionável & Demanda ajuste \\
\hline & & Demanda ajuste & Calculável \\
\hline & & Demanda ajuste & Demanda ajuste \\
\hline & \multirow{4}{*}{ Demanda ajuste } & Operacionável & Calculável \\
\hline & & Operacionável & Demanda ajuste \\
\hline & & Demanda ajuste & Calculável \\
\hline & & Demanda ajuste & Demanda ajuste \\
\hline \multirow{7}{*}{ 3. Não Executável } & \multirow{3}{*}{ Compreensível } & Não operacionável & Demanda ajuste \\
\hline & & Não operacionável & Não calculável \\
\hline & & Demanda ajuste & Não calculável \\
\hline & \multirow{4}{*}{ Demanda ajuste } & Operacionável & Não calculável \\
\hline & & Não operacionável & Demanda ajuste \\
\hline & & Não operacionável & Não calculável \\
\hline & & Demanda ajuste & Não calculável \\
\hline 4. Não Executável & Incompreensível & - & - \\
\hline
\end{tabular}

Ainda com respeito ao diagnóstico, importante destacar que não houve análise da unidade de medida e método de apuração, quando o enunciado foi classificado como "incompreensível", uma vez que este é o elemento essencial da análise para o diagnóstico da meta.

Considerando a abordagem quantitativa da pesquisa, como técnica de análise foi utilizada a estatística descritiva com a finalidade de identificar a frequência de uso das metas pelos museus no período analisado (2011 a 2015), por meio da sintetização de uma série de valores de uma mesma natureza. A estatística descritiva permitiu uma visão global sobre a variação, organização e descrição das metas por museu, por meio de tabelas. Todas as tabelas foram elaboradas com o auxílio do programa Microsoft Excel®, usando a função "tabela dinâmica". 
O Quadro 4 representa de forma sintetizada as ações que foram desenvolvidas pelo pesquisador com o intuito de atingir os objetivos desta pesquisa.

QUADRO 4 - Objetivos, ações e técnica de análise

\begin{tabular}{|c|c|c|}
\hline Objetivos & Ações & Técnica de análise \\
\hline $\begin{array}{l}\text { Mapear todas as metas } \\
\text { adotadas pelas unidades } \\
\text { museológicas para } \\
\text { consolidação de uma lista } \\
\text { única }\end{array}$ & $\begin{array}{c}\text {-> Relaciona as metas } \\
\text {-> Verificar similaridades } \\
\text {-> Consolidar as metas em } \\
\text { uma lista única }\end{array}$ & Análise de conteúdo \\
\hline $\begin{array}{l}\text { Analisar a consistência e } \\
\text { aplicabilidade das metas }\end{array}$ & $\begin{array}{l}\text {-> Analisar as metas quanto } \\
\text { a coerência, objetividade, } \\
\text { compreensibilidade, } \\
\text { operacionalidade, } \\
\text { tangibilidade, especificação } \\
\text { da fonte de informação e } \\
\text { executabilidade } \\
\text {-> Identificar a frequência } \\
\text { das metas de acordo com o } \\
\text { seu diagnóstico }\end{array}$ & $\begin{array}{l}\text { Análise de conteúdo e } \\
\text { estatística descritiva }\end{array}$ \\
\hline
\end{tabular}

Com base nas técnicas de análise apresentadas, o próximo capítulo apresenta e analisa os resultados obtidos.

\section{APRESENTAÇÃO E ANÁLISE DOS RESULTADOS}

Neste tópico serão apresentados os resultados e as análises para cada uma das partes do presente estudo, sendo que a primeira trata da consolidação das metas por unidade museológica, permitindo uma visão geral da quantidade de metas utilizadas por museus, ao passo que a segunda aborda a análise da consistência e aplicabilidade das metas.

\section{METAS POR UNIDADE MUSEOLÓGICA}

Esta seção propõe-se a apresentar, por meio de tabelas e com o uso da estatística descritiva, as metas utilizadas pelos museus unidade II e III no período de 2011 a 2015. É importante salientar que as unidades museológicas II e III correspondem a um total de 16 (dezesseis) unidades de gestão, ressalvando que o Museu de Arte Sacra de Paraty e Forte Defensor Perpétuo de Paraty vinculados a uma mesma gestão, sendo aqui denominados de Museus Paraty, assim como ocorre com o Museu das Bandeiras, Museu Casa da Princesa e Museu de Arte Sacra da Boa Morte, que estão representados por Museus Goiás.

A consolidação de todas as metas das unidades museológicas, com o auxílio do Microsoft Excel ${ }^{\circledR}$, evidenciou um total de 410 metas utilizadas no período. Após a consolidação, obteve-se a primeira tabela (Tabela 1) que detalha a quantidade de metas por museu e por ano. Vale relembrar que, em 2013, apenas três (3) museus informaram suas metas institucionais, uma vez que o IBRAM, por não incluir as metas 
dos museus em suas metas intermediárias, não solicitou aos museus que as informassem.

TABELA 1 - Número de Metas usadas pelos museus no período (2011 - 2015)
\begin{tabular}{|l|c|c|c|c|c|c|}
\hline Museu & $\mathbf{2 0 1 1}$ & $\mathbf{2 0 1 2}$ & $\mathbf{2 0 1 3}$ & $\mathbf{2 0 1 4}$ & $\mathbf{2 0 1 5}$ & Total \\
\hline Museu Casa da Hera & 7 & 12 & - & 14 & 5 & 38 \\
\hline Museu Casa de Benjamin Constant & 4 & 4 & - & 4 & 5 & 17 \\
\hline Museu Casa Histórica de Alcântara & 7 & 6 & 4 & 4 & 5 & 26 \\
\hline Museu da Abolição & 5 & 6 & - & 3 & 3 & 17 \\
\hline Museu das Missões & 5 & 5 & - & 4 & 5 & 19 \\
\hline $\begin{array}{l}\text { Museu de Arqueologia/ } \\
\text { Socioambiental de Itaipu }\end{array}$ & 5 & 4 & - & 3 & 7 & 19 \\
\hline $\begin{array}{l}\text { Museu de Arte Religiosa e } \\
\text { Tradicional }\end{array}$ & 5 & 7 & 6 & 5 & 4 & 27 \\
\hline Museu do Diamante & 6 & 6 & - & 5 & & 17 \\
\hline Museu do Ouro - Casa Borba Gato & 1 & 1 & - & 1 & 2 & 5 \\
\hline Museu Regional Casa dos Ottoni & 6 & 5 & - & 5 & 5 & 21 \\
\hline Museu Regional de Caeté & 8 & 5 & - & 5 & 5 & 23 \\
\hline $\begin{array}{l}\text { Museu Regional de São João del- } \\
\text { Rei }\end{array}$ & 9 & 11 & - & 9 & 9 & 38 \\
\hline Museu Solar Monjardim & 3 & 2 & - & 2 & 2 & 9 \\
\hline Museu Victor Meirelles & 14 & 13 & 11 & 10 & 10 & 58 \\
\hline Museus Goiás & 11 & 20 & - & 5 & 4 & 40 \\
\hline Museus Paraty & 11 & 10 & - & 7 & 8 & 36 \\
\hline Total Geral & $\mathbf{1 0 7}$ & $\mathbf{1 1 7}$ & $\mathbf{2 1}$ & $\mathbf{8 6}$ & $\mathbf{7 9}$ & $\mathbf{4 1 0}$ \\
\hline
\end{tabular}

FONTE: Elaborado pelos autores a partir dos dados da pesquisa.

A partir desta primeira tabela é possível identificar que a maior quantidade de metas adotadas pelos museus ocorreu nos dois primeiros anos (2011 e 2012) logo após a criação do IBRAM (2009), percebendo-se uma diminuição nos anos seguintes (2014 e 2015), não considerando o ano de 2013, uma vez que apenas três museus informaram suas metas institucionais.

Observa-se ainda que a quantidade de metas adotadas por cada museu é muito variada, havendo museus que adotaram uma meta por ano, a museus que adotaram 20 (vinte). Lembrando que Museus Goiás compreende a administração de três unidade museológicas.

Com relação à utilização das metas, percebeu-se que há uma grande descontinuidade em sua aplicação, uma vez que a maioria das metas foram utilizadas apenas uma vez. Ainda sobre a utilização das metas pelas unidades museológicas pesquisadas, o Quadro 5 destaca as metas que foram utilizadas por mais de um museu.

QUADRO ${ }_{5}$ - Relação das Metas mais utilizadas pelos museus

\begin{tabular}{|l|c|}
\hline \multicolumn{1}{|c|}{ Metas } & $\begin{array}{c}\text { Total de } \\
\text { Museus }\end{array}$ \\
\hline 1. Realização de Exposições Temporárias & 7 \\
\hline 2. Revisão do Plano Museológico & 3 \\
\hline 3. Capacitação de Servidores & 2 \\
\hline
\end{tabular}




\begin{tabular}{|l|c|}
\hline 4. Incremento da visitação ao museu de 50\% em relação ao ano de 2010 & 2 \\
\hline 5. Participação na Semana de Museus e na Primavera dos Museus & 2 \\
\hline 6. Realização de atividades culturais e educativas & 2 \\
\hline 7. Realização de atividades educativas & 2 \\
\hline 8. Realização de eventos no museu & 2 \\
\hline
\end{tabular}
FONTE: Elaborado pelos autores a partir dos dados da pesquisa.

Como mencionado, foram identificadas 410 metas, sendo que apenas 8 foram utilizadas por mais de um museu no período em estudo. É importante frisar que a falta de padronização na redação das metas pode ter comprometido o resultado apresentado, pois algumas metas possuíam o mesmo objetivo, mas continham redação distinta.

\section{ANÁLISE DA CONSISTÊNCIA E APLICABILIDADE DAS METAS}

Esta seção destina-se a apresentar a análise de consistência e aplicabilidade do total das 410 metas utilizadas pelos Museus Ibram (unidades II e III) no período de 2011 a 2015 . A análise da consistência avaliou os três elementos que compõem cada uma das metas: enunciado, unidade de medida e método de apuração. A avaliação quanto a aplicabilidade deu-se a partir da conjugação do resultado dos três elementos da meta. Esta, seguramente, foi a análise mais complexa de todo o contexto deste trabalho.

Cada enunciado foi avaliado segundo o critério de compreensibilidade, sendo classificado como compreensível, demanda ajuste e incompreensível. Com relação à unidade de medida, esta teve como critério a sua operacionalidade, sendo classificada como operacionável, demanda ajuste e não operacionável.

Por último, foi avaliado o método de apuração, que considerou o método quanto a viabilidade de cálculo, classificando-o como calculável, demanda ajuste e não calculável. Todas estas classificações encontram-se detalhas na metodologia desta pesquisa (Quadro 3).

A Tabela 2 consolida o resultado da avaliação de todos os enunciados, unidades de medida e métodos de apuração descritos em cada uma das 410 metas avaliadas.

TABELA 2 - Análise dos Elementos das Metas

\begin{tabular}{|l|c|c|}
\hline Informação & Frequência & Percentual \\
\hline & & \\
\hline Enunciado & & $51 \%$ \\
\hline Compreensível & 208 & $34 \%$ \\
\hline Demanda ajuste & 139 & $15 \%$ \\
\hline Incompreensível & 63 & \\
\hline & & \\
\hline Unidade de Medida & & \\
\hline
\end{tabular}




\begin{tabular}{|l|c|c|}
\hline Informação & Frequência & Percentual \\
\hline Operacionável & 312 & $76 \%$ \\
\hline Demanda ajuste & 61 & $15 \%$ \\
\hline Não Operacionável & 37 & $9 \%$ \\
\hline & & \\
\hline Método de Apuração & 275 & $67 \%$ \\
\hline Calculável & 93 & $10 \%$ \\
\hline Demanda ajuste & 42 & \\
\hline Não calculável & & \\
\hline & & \\
\hline
\end{tabular}

Pelo resultado acima apresentado, é possível inferir que há um alto percentual de falha na construção das metas institucionais pelas unidades museológicas analisadas, como pode ser observado pelo percentual de metas que demandam ajuste em seu enunciado, unidade de medida e método de apuração.

Um dos principais problemas encontrado na avaliação do enunciado foi a falta de objetividade, pois muitos dos enunciados referiam-se a mais de um objetivo ou ação a ser realizadas, outros, apesar de convergirem para uma única temática, não eram específicos quanto ao que se pretendia alcançar. Muito embora, ao analisar a unidade de medida e método de apuração, foi possível deduzir o objetivo desejado. Então, nestes casos, o enunciado demanda algum ajuste para que esta meta possa ser utilizada novamente.

De acordo com o percentual de enunciados classificados como "demanda ajuste" e "incompreensível", totalizando $49 \%$, fica evidente que há uma deficiência na construção da redação dos enunciados.

Com relação à unidade de medida, percebe-se que poucas demandam ajuste ou são não operacionáveis, apenas $24 \%$, consideram o resultado da avaliação do enunciado. As principais causas das falhas na escolha da unidade de medida foram a falta de compatibilidade com o enunciado ou com o método de apuração.

Por fim, temos a análise do método de apuração, o qual também apresenta um resultado melhor do que a análise do enunciado, contudo inferior quando comparado à unidade de medida. Observa-se que $33 \%$ dos métodos utilizados ou demandam ajuste ou não são calculáveis. As principais causas identificadas na análise foram a falta de compatibilidade com o enunciado ou unidade de medida e a inversão da relação dividendo/divisor na fórmula de cálculo estabelecida.

Com a finalização da avaliação do enunciado, unidade de medida e método de apuração, foi possível realizar o diagnóstico das metas. Para tanto, feita a tabulação dos dados das avaliações de cada meta e, em seguida, a análise da combinação dos três resultados obtidos com o guia de diagnóstico (Quadro 3).

O diagnóstico geral apresentado corrobora com o resultado obtido com a avaliação dos elementos da meta isoladamente. Verifica-se 


\section{Revista de Gestão Pública}

um baixo percentual de metas executáveis sem a necessidade de ajuste ou correção, representando um total aproximado de $41 \%$, ou seja, menos da metade das metas utilizadas pelos museus são executáveis.

Desta forma, a maioria das metas ou necessitam de ajustes (37\%) ou não são executáveis ( $22 \%)$, evidenciando, mais uma vez, a deficiência dos museus na escolha e construção de suas metas.

A Tabela 3 sintetiza o resultado do diagnóstico, por unidade museológica, das 410 metas analisadas. Analisando a segunda coluna de diagnóstico, o Museu Casa Histórica de Alcântara, Museu da Abolição, Museu Solar Monjardim e Museus Goiás destacam-se por terem apresentado maior percentual de metas diagnosticadas como executáveis, acima de $70 \%$.

Já em relação as metas que necessitam de ajustes, o Museu Casa da Hera, Museu Casa Benjamin, Museu de Arqueologia/Socioambiental de Itaipu, Museu do Ouro - Casa Borba Gato, Museu Victor Meirelles foram os que apresentaram o maior percentual de metas executáveis com ajuste, destacando-se o Museu do Ouro - Casa Borba Gato que apresentou o maior índice ( $80 \%$ ). Cabe observar que este alto percentual obtido pelo Museu do Ouro se deve ao fato de ter adotado apenas duas metas distintas no período analisado.

TABELA 3 - Diagnóstico das Metas por Museu

\begin{tabular}{|c|c|c|c|c|c|c|c|}
\hline \multirow{3}{*}{ Museus } & \multicolumn{6}{|c|}{ Diagnóstico das Metas } & \multirow{3}{*}{$\begin{array}{c}\text { Metas } \\
\text { analisadas }\end{array}$} \\
\hline & \multicolumn{2}{|c|}{ Executável } & \multicolumn{2}{|c|}{$\begin{array}{c}\text { Executável com } \\
\text { ajuste }\end{array}$} & \multicolumn{2}{|c|}{ Não executável } & \\
\hline & Freq. & $\%$ & Freq. & $\%$ & Freq. & $\%$ & \\
\hline Museu Casa da Hera & 7 & 18,4 & 19 & 50,0 & 12 & 31,6 & 38 \\
\hline Museu Casa de Benjamin Constant & 4 & 23,5 & 12 & 70,6 & 1 & $5,9 \%$ & 17 \\
\hline Museu Casa Histórica de Alcântara & 25 & 96,2 & 1 & 3,8 & - & - & 26 \\
\hline Museu da Abolição & 16 & 94,1 & 1 & 5,9 & & - & 17 \\
\hline Museu das Missões & 13 & 68,4 & 3 & 15,8 & 3 & 15,8 & 19 \\
\hline Museu de Arqueologia/Socioambiental de Itaipu & 4 & 21,1 & 11 & 57,9 & 4 & 21,1 & 19 \\
\hline Museu de Arte Religiosa e Tradicional & 7 & 25,9 & 8 & 29,6 & 12 & 44,4 & 27 \\
\hline Museu do Diamante & 7 & 41,2 & 4 & 23,5 & 6 & 35,4 & 17 \\
\hline Museu do Ouro - Casa Borba Gato & - & - & 4 & 80,0 & 1 & 20,0 & 5 \\
\hline Museu Regional Casa dos Ottoni & 2 & 9,5 & 6 & 28,6 & 13 & 61,9 & 21 \\
\hline Museu Regional de Caeté & 11 & 47,8 & 8 & 34,8 & 4 & 17,4 & 23 \\
\hline
\end{tabular}




\begin{tabular}{|c|c|c|c|c|c|c|c|}
\hline \multirow{3}{*}{ Museus } & \multicolumn{6}{|c|}{ Diagnóstico das Metas } & \multirow{3}{*}{$\begin{array}{c}\text { Metas } \\
\text { analisadas }\end{array}$} \\
\hline & \multicolumn{2}{|c|}{ Executável } & \multicolumn{2}{|c|}{$\begin{array}{c}\text { Executável com } \\
\text { ajuste }\end{array}$} & \multicolumn{2}{|c|}{ Não executável } & \\
\hline & Freq. & $\%$ & Freq. & $\%$ & Freq. & $\%$ & \\
\hline Museu Regional de São João del-Rei & 11 & 28,9 & 16 & 42,1 & $11-$ & 28,9 & 38 \\
\hline Museu Solar Monjardim & 8 & 88,9 & 1 & 11,1 & - & - & 9 \\
\hline Museu Victor Meirelles & 11 & 19,0 & 34 & 58,6 & 13 & 22,4 & 58 \\
\hline Museus Goiás & 30 & 75,0 & 8 & 20,0 & 2 & 5,0 & 40 \\
\hline Museus Paraty & 11 & 30,6 & 17 & 47,2 & 8 & 22,2 & 36 \\
\hline Total Geral & 167 & 40,7 & 153 & 37,3 & 90 & 22,0 & 410 \\
\hline
\end{tabular}

Por fim, observa-se-se o diagnóstico com as metas classificadas como não executáveis, que representa $22 \%$ do total das metas analisadas, ressaltando o Museu Casa da Hera, Museu de Arte Religiosa e Tradicional, Museu do Diamante e Museu Regional Casa dos Ottoni que apresentaram um resultado superior a $30 \%$.

\section{CONCLUSÃO}

Como objetivo principal, o presente trabalho buscou analisar a consistência e aplicabilidade das metas adotadas pelos museus unidades II e III, vinculados ao Instituto Brasileiro de Museus - IBRAM, no período de 2011 a 2015 , através do mapeamento de todas as metas utilizadas por unidade museológica.

Observou-se, a partir da frequência de uso apresentada, que há uma descontinuidade no uso das metas, uma vez que maioria foi utilizada apenas uma única vez, no período de 5 anos. E, considerando que as metas utilizadas pelos museus do IBRAM se assemelham a indicadores, pela forma como foram estruturadas, esta falta de continuidade em sua utilização pode comprometer a avaliação do desempenho das unidades museológica, uma vez que não há parâmetros para comparação da evolução das ações no decorrer dos anos. Isto significa que as metas de desempenho não tem sido utilizadas pelos museus investigados de maneira adequada e que sua aplicabilidade enquanto instrumento gerencial tem sido limitado e sem consistência capaz de nortear decisões estratégicas para o aprimoramento de gestão.

Além da descontinuidade no uso das metas, o elevado índice de falhas relacionadas à redação do enunciado, à escolha da unidade de medida e à construção do método de apuração pode dificultar a compreensão, comprometer o alcance das metas e, consequentemente, a avaliação do resultado, pois podem não corresponder aos objetivos que deveriam ser 
alcançados. Vale ressaltar que, uma vez que essas metas compõem as metas intermediárias do IBRAM, este também poderá ter seus resultados afetados. Diante disso, pode-se concluir que o processo de concepção das metas possui fragilidades que precisam ser identificadas e corrigidas.

O mesmo se aplica à aplicabilidade das metas. . Uma vez que a maioria das metas utilizadas encontram-se comprometidas, ou seja, apresentam alguma falha em sua construção, evidenciando a necessidade da implementação de programas de capacitação, tanto para os gestores, quanto para os servidores das unidades museológicas cujas as metas foram analisadas. Estas ações corretivas serão úteis para a especificação e construção das metas institucionais, assim como, na padronização de linguagem para a redação do texto dos enunciados.

Ainda com relação às falhas identificadas na definição e composição das metas durante o período analisado, especialmente quanto ao método de apuração, nota-se que estas falhas são recorrentes ao longo dos anos, assim, pode-se inferir que não há uma avaliação das metas enviadas ao IBRAM, tão pouco um feedback aos gestores dos museus sobre as metas utilidades, e que a adoção de metas tem servido apenas para o cumprimento de uma exigência legal.

Em face do exposto, espera-se que os resultados deste trabalho possam trazer contribuições teóricas para o campo museal, assim como práticas para os profissionais da área, assim como contribuir para um processo de melhoria na gestão dos museus, especialmente na gestão, desempenho e resultados dos museus públicos federais administrados pelo IBRAM.

\section{REFERÊNCIAS}

ALONSO, M. Custos no serviço público. Revista do Serviço Público, v. 50, n. 1, p. 37-63, 1999.

ANDRADE, M. M. Introdução à metodologia do trabalho científico. 4ed. São Paulo: Atlas; 1999.

ARAÚJO, M. A. D. Responsabilização pelo controle de resultados no Sistema Único de Saúde no Brasil.

Rev. Panam Salud Pública 2010; 27:230-6.

BANDEIRA DE MELLO, C. A. Curso de Direito

Administrativo. 28. ed. São Paulo: Malheiros, 2011.

BRASIL. Presidência da República. Constituição da

República Federativa do Brasil. Brasília, DF, 1988.

Disponível em: <http://www.planalto.gov.br/ccivil_03/

constituicao/constituicao.htm>. Acesso em 23 jun. 2016.

. Ministério do Planejamento, Orçamento

e Gestão. Secretaria de Gestão. Gestão pública

para um Brasil de todos: um plano de gestão para 
o Governo Lula. Brasília: MP, SEGES, 2003.

. Decreto no 2.829, de 29 de outubro

de 1998. Diário Oficial da União, Poder

Executivo, 29 de outubro de 1998. Seção 1.

. Emenda Constitucional no ${ }^{0}$ 19, de 04

de junho de 1998. Diário Oficial da União, Poder

Executivo, o6 de junho de 1998. Seção 1.

. Lei $\mathrm{n}^{\mathrm{o}} 11.784$, de 22 de setembro de

2008. Diário Oficial da União, Poder Executivo,

23 de setembro de 2008. Seção 1.

. Lei $\mathrm{n}^{\mathrm{0}}$ 11.906, de 20 de janeiro de 2009. Diário Oficial

da União, Poder Executivo, 20 de janeiro de 2009. Seção 1.

. Lei no 9.989 - PPA 2000-2003, de 21

de julho de 2000. Diário Oficial da União, Poder

Executivo, 21 de julho de 2000. Seção 1.

. Lei Complementar n⿳o 101, de 04 de maio de

2000. Diário Oficial da União, Poder Executivo, 04 de

maio de 2000. Seção 1. . Orientação Normativa

n⿳0 07, de 31 de agosto de 2011. Diário Oficial da União,

Poder Executivo, 31 de agosto de 2011. Seção 1.

. Ministério do Planejamento, Orçamento e

Gestão. Secretaria de Gestão. Programa Nacional de Gestão

Pública e Desburocratização - GesPública; Prêmio Nacional

da Gestão Pública - PQGF; Documento de Referência;

Fórum Nacional 2008/2009 / Ministério do Planejamento,

Orçamento e. Gestão, Subsecretaria de Planejamento,

Orçamento e Gestão. - Brasília: MP, SEGES, 2009. 56 p.

. Decreto $n^{\mathrm{o}}$ 7.133, de 19 de março de

2010. Diário Oficial da União, Imprensa Nacional,

Brasília, 22 de mar. 2010. Seção 1, p. 1.

. Ministério do Meio Ambiente. Instituto

Brasileiro do Meio Ambiente e dos Recursos Renováveis Ibama. Avaliação de Desempenho Individual - Manual de procedimentos para aplicação, Brasília. 2011.

. Ministério do Planejamento, Orçamento e

Gestão. Secretaria de Orçamento Federal. Secretaria de Planejamento e Investimentos Estratégicos. Indicadores Orientações Básicas Aplicadas à Gestão Pública / Ministério do Planejamento, Orçamento e Gestão. Coordenação de Documentação e Informação - Brasília: MP, 2012. 64 p.: il. color. 
. Ministério do Planejamento, Orçamento

e Gestão. Manual de Orientação para a Gestão do Desempenho, Brasília; MP, SEGEP, 2013.

. Ministério do Planejamento, Orçamento e Gestão. Programa GESPÚBLICA, Modelo de Excelência em Gestão Pública, Brasília; MP, SEGEP, 2014.

BRESSER-PEREIRA, L. C. O modelo estrutural de gerência pública. Revista de Administração Pública, Mar./Abr., p. 391-410, 2008. . Gestão do setor público: estratégia e estrutura para um novo Estado. Reforma do Estado e Administração Pública Gerencial, v. 7., p. 21-38, 2006.

CORREAA, I. M. Planejamento estratégico e gestão pública por resultados no processo de reforma administrativa do estado de Minas Gerais. Revista de Administração Pública, v. 41, n. 3, p. 487-504, 2007.

CRESWELL, J. W. Projeto de pesquisa: métodos qualitativo, quantitativo e misto. 3. ed. Porto Alegre: Artmed, 2010.

CRESWELL, J. W. Investigação qualitativa e projeto de pesquisa: escolhendo entre cinco abordagens. 3. ed. Porto Alegre: Penso, 2014.

DE OLIVEIRA, C. E. M. Avaliação de desempenho em Instituições Federais de Ensino Superior: aplicação do Balanced Scorecard. 2007. Tese de Doutorado. UNIVERSIDADE FEDERAL DE ITAJUBÁ.

FERREIRA, A. R. Modelo de excelência em gestão pública. Revista Eixo, v. 1, n. 1, p. 31-43, 2012.

FREITAS, V. P. de; CARDOSO, R. L.; AQUINO, A. C. B. de.; REIS JR., R. C. Mensuração de desempenho em organizações públicas: o caso da Secretaria da Fazenda do Rio Grande do Sul. Revista do Serviço Público. Brasília. 6o (3): 277-290. Jul/Set, 2009.

FONSECA, J. J. S. da. Metodologia da pesquisa científica. Fortaleza: UEC, 2002. Apostila.

FURTADO, M.; FORTUNATO, G.; TEIXEIRA, A. A. Gestão pública e de projetos: um estudo sobre a percepção dos gestores no gerenciamento de projetos no governo do Estado do espírito santos. In: V Congresso ANPCONT, 2011.

GALDINO, J. A.; GUIMARÃES, M. G. V.; CARMO FILHO, M. M. Análise do desempenho na gestão pública das 
despesas orçamentárias com segurança pública no Brasil.

Revista Ambiente Contábil, v. 7, n. 1, p. 70-88, 2015.

GARCES, A.; SILVEIRA, J. P. Gestão pública orientada para resultados no Brasil. Revista do Serviço

Público, Ano 53, v. 4, p. 53-77, out-dez, 2002.

GIL, A. C. Métodos e técnicas de pesquisa

social. 5d. São Paulo: Atlas; 1999.

GOMES, E. G. M. Gestão por Resultados e eficiência na Administração Pública: uma análise à luz da experiência de Minas Gerais. Tese de Doutorado. Fundação Getúlio Vargas. Escola de Administração de Empresas de São Paulo. São Paulo, 2009.

GONZAGA, R. P. A efetividade do acordo de resultados no choque de gestão: um estudo sobre as alterações dos indicadores de desempenho. Tese de Doutorado. Universidade de São Paulo. Faculdade de Economia, Administração e Contabilidade. São Paulo, 2014.

HEINRICH, C. J. Measuring public sector performance and effectiveness. The SAGE Handbook of

Public Administration, v. 2, p. 24-38, 2003.

INSTITUTO BRASILEIRO DE MUSEUS. Subsídios para a elaboração de planos museológicos. Brasília, 2016.

JOHNSEN, A. What does 25 years of experience tell us about the state of performance measurement in public policy and management?. Public Money and Management, 2005, 25.1: 9-17.

JULIÃO, C. M.; LIBONATI, J. J.; SANTOS, A. A. O Uso de indicadores de desempenho no modelo de Gestão Todos por Pernambuco. 2012. Disponível em: < https://www.ufpe.br/ppgcontabeis/images/ documentos/artclayton.pdf $>$. Acesso em 28 jun. 2016.

JULIÃO, C. M. O uso de indicadores de desempenho: um estudo de caso sobre a aderência do modelo de gestão Todos por Pernambuco à Literatura. 2014. Dissertação. Disponível em: < http://repositorio.ufpe.br/ handle/123456789/11510>. Acesso em: 27 Jun. 2016.

LIMA JR., O. B. As reformas administrativas no Brasil: modelos, sucessos e fracassos. Revista do Serviço Público, 49(2), abril-junho, 1998. p. 5-31.

MAIA, J. L.; OLIVEIRA, G. T. de; MARTINS, R. A. O 
papel da medição de desempenho no processo estratégico: uma tentativa de síntese teórica. Revista Eletrônica

Sistemas \& Gestão, v. 3, n. 2, p. 129-146, 2008.

MARTINS, H.F.; MARINI, C. Um guia de governança para resultados na administração pública. Brasília, DF: Publix, 2010.

MATIAS-PEREIRA, J. Manual da gestão pública contemporânea. 2.ed. São Paulo: Atlas, 2009.

MUSEUS IBRAM. IBRAM. Disponível em: <http://www.museus. gov.br/os-museus/museus-ibram/>. Acesso em: 30 jul. 2017.

NEELY, A.; GREGORY, M.; PLATTS, K. Performance measurement system design: a literature review and research agenda. International Journal of Operations \& Production Management, v. 15, n. 4, p.80-116, 1998.

NEELY, A. Business Performance Measurement: unifying theory and integrating pratice. $2 \mathrm{ed}$. Cambridge Univerrsity Press, 2007.

NOGUEIRA, J. M. M.; GÓIS, L. de O. L.; PACHECO, R. S. V. M. A gestão do poder judiciário: uma análise do sistema de mensuração de desempenho do judiciário brasileiro. 2010. Disponível em: < http://banco.consad. org.br/handle/123456789/83>. Acesso em 28 jun. 2016.

NEVES, E. B.; DOMINGUES, C. A. Manual de metodologia da pesquisa científica. Rio de Janeiro: EB/CEP, 2007

OLIVEIRA, S. K. de. Modelo de avaliação de desempenho de gestão para hospitais secundários no setor público brasileiro. 2009. Dissertação. Disponível em: < http://www.gespublica.gov. br/content/modelo-de-avalia $\% \mathrm{C}_{3} \% \mathrm{~A}_{7} \% \mathrm{C}_{3} \% \mathrm{~A}_{3} \mathrm{O}$-de-desempenhode-gest $\% \mathrm{C}_{3} \% \mathrm{~A}_{3} \mathrm{O}$-para-hospitais-secund $\% \mathrm{C}_{3} \%$ Atriosno-setor-p\%C3\%BAblico>. Acesso em: 11 jul. 2016.

PACHECO, R. S. Mensuração de desempenho no Setor Público: os termos do debate. II Congresso Consad de Gestão Pública - Painel 13: Enfrentando as dificuldades de mensuração de desempenho no setor público: experiências em curso no Brasil, 2009.

PALVARINI, B. Guia referencial de mensuração do desempenho na administração pública. 2010. Disponível em: <http://banco. consad.org.br/handle/123456789/254>. Acesso em 29 jun. 2016.

PERDICARIS, P. R. Gestão para resultados como política pública: uma análise da formação da agenda e formulação de alternativas em municípios brasileiros. Dissertação 
(Mestrado em Administração Pública e Governo) - Fundação Getúlio Vargas, São Paulo, São Paulo, Brasil, 2009.

PRODANOV, C. C.; FREITAS, E. C. de. Metodologia do trabalho científico: métodos e técnicas da pesquisa e do trabalho acadêmico. - 2. ed. - Novo Hamburgo: Feevale, 2013.

PUTNAM, R. D. Comunidade e democracia: a experiência da Itália moderna. Rio de Janeiro: Fundação Getúlio Vargas, 2007.

RAFAELI, L.; MÜLLER, C. J. Estruturação de um índice consolidado de desempenho utilizando o AHP. Gestão \& Produção, v. 14, n. 2, p. 363-377, 2007.

ROGERS, G.; BADHAM, L. Evaluation in the management cycle. Improving educational management through research and consultancy. London: Paul Chapman Publishing, 1994.

SANO, H.; ABRUCIO, F. L. Promessas e resultados da Nova Gestão Pública no Brasil: o caso das organizações sociais de saúde em São Paulo. Revista Administração de Empresas, São Paulo, v. 48, n. 3, p. 64-80, Sept. 2008. Disponível em: $<$ http://www.scielo.br/scielo.php?script=sci_arttext\&pid=So03475902008000300007\&lng=en\&nrm=iso >. Acesso em: 14 June 2016.

SANTANA, W. C.; PIZZOLATO, N. D. Proposta de modelo de desenvolvimento de sistema de medição de desempenho logístico. 2004. Tese de Doutorado. Dissertação (Mestrado em Logística do Departamento de Engenharia Industrial). Pontifícia Universidade Católica do Rio de Janeiro, PUC-Rio. Disponível em: < http://www.maxwell.vrac.puc-rio.br/Busca_etds. php?strSecao=resultado\&nrSeq=6063@1>. Acesso em: 11 Jul. 2016.

SANTOS, I. E. dos. Métodos e técnicas de pesquisa científica. 4. ed. Rio de Janeiro: Impetus, 2003.

SANTOS, P. M.; SELIG, P. M. Indicadores para o novo serviço público: uma análise bibliométrica e sistêmica. Perspectivas em Ciência da Informação, v. 19, n. 3, p. 82-97, 2014.

SILVA, I. L. da; DRUMOND, R. B. A necessidade da utilização de sistema de custos e de indicadores de desempenho na administração pública. In: Congresso USP de Controladoria e Contabilidade. 2004.

SECCHI, L. Modelos organizacionais e reformas da administração pública. Revista de Administração Pública, Rio de Janeiro, v. 43, n. 2, mar./abr. 2009. Disponível em: < http://www.scielo.br/pdf/rap/ v43n2/v43n2ao4.pdf>. Acesso em: 14 Jul 2016. 
SILVA, E. L. da; MENEZES, E. M. Metodologia da pesquisa e elaboração de dissertação. 4. ed. rev. atual. Florianópolis: UFSC, 2005. 138p.

SILVA, E. G. Desempenho institucional em uma universidade pública. C\&D Revista Eletrônica da Fainor, v. 2, n. 1, p. 13-32, 2009.

SILVA, C. A. G. DA; CROZATTI, J. A demonstração do resultado econômico na gestão de políticas públicas: Avaliação da aplicabilidade pelos auditores da Secretaria Municipal de Finanças da Prefeitura de São Paulo. Revista de Contabilidade e Controladoria, v. 5, n. 2, p. 8-24, maio/ago. 2013.

SOUZA, M. A. de.; MAUSS, C. V.; DIEHL, C. A.; BLEIL, C. A gestão pública por resultados e a avaliação de desempenho. In: Congresso USP de Controladoria e Contabilidade, 8., 2008, São Paulo, Anais... São Paulo: USP, 2008.

SOUZA, D. L. de. Planejamento Estratégico em Organizações Públicas. Planejamento de longo prazo em organizações públicas com a utilização do Balanced Scorecard e de cenários prospectivos. Monografia. 2010. Universidade Gama Filho, Brasília. Disponível em: < http://portal2.tcu.gov.br/ portal/pls/portal/docs/2507576.PDF>. Acesso em: 12 Jul. 2016.

STRAUSS, A.; CORBIN, J. M. Basics of qualitative research: Grounded theory procedures and techniques. Sage Publications, Inc, 1990.

SUZUKI, J. A. Noguchi; GABBI, L. V. B. Desafios da avaliação de desempenho no setor público: o caso da prefeitura municipal de São Paulo. 2009. In: II Congresso Consad de Gestão Pública - Painel 13: Enfrentando as dificuldades de mensuração.

TAKASHINA, N. T.; FLORES, M. C. X. Indicadores da qualidade e do desempenho: como estabelecer metas e medir resultados. Rio de Janeiro: Qualitymark, 1996.

TALBOT, C.; DAUNTON, L.; MORGAN, C. A mensuração do desempenho de ministérios e agências de governo: evoluções internacionais. Revista do Serviço Público, v. 52, n. 3, p. 5-51, 2001.

TEZZA, R.; BORNIA, A. C.; VEY, I. H. Sistemas de medição de desempenho: uma revisão e classificação da literatura. Gestão da Produção, São Carlos, v. 17, n. 1, p. 75-93, 2010.

VELASCO, S. M. V. de; SILVA, M. T. Sistemática da avaliação de desempenho na Administração Pública Federal. In: Congresso CONSAD de Gestão Pública, 4, 2011, Brasília. Anais... 
VERGARA, S. C. Projetos e relatórios de pesquisa em administração. 4ed. São Paulo: Atlas; 2003.

VILHENA, R.; MARTINS, H. F.; MARINI, C.; GUIMARÃES, T. B. O choque de gestão em Minas Gerais: políticas da gestão pública para o desenvolvimento. Belo Horizonte: Editora UFMG, p. 95-144, 2006.

XAVIER, J. S. Plano museológico: uma discussão para o Museu de Arqueologia Bíblica Paulo Bork do Centro Universitário Adventista de São Paulo. Dissertação.

Universidade de São Paulo. São Paulo, 2015.

ZUCATTO, L. C.; SARTOR, U. M.; BEBER, S.; WEBER, R. Proposição de indicadores de desempenho na gestão pública. ConTexto, Porto Alegre, v. 9, n. 16, p. 1-24, 2009. 